\title{
GENTILMANTARIMAY: La función que desempeñaban los Intihuatanas, como el de Machu Picchu
}

\author{
Federico Kauffmann Doig ${ }^{1, a, \sqrt{\equiv}}$ \\ ${ }^{1}$ Museo de Arte, Director General del Patrimonio Monumental y Cultural de la Nación y Director del Museo Nacional de Antropología y Arqueología e Historia del \\ Perú \\ a Doctor en Arqueología y en Historia \\ ”fkauffmanndoig@gmail.com
}

Citar como:

Kauffmann Doig, F. (2019). GENTILMANTARIMAY: La función que desempeñaban los intihuatanas, como el de Machu Picchu. Rev Yachay, 8(1), 612.

Recibido: 15-09-2019; Aceptado 12-12-2019; Publicado 12-12-2019

Como lo revela el título dado al presente documento, en las líneas siguientes intentaremos ofrecer una interpretación de la función que correspondía a los intihuatana y en particular al de Machu Picchu.

Para dar cumplimiento a este objetivo, nos servimos de un mito recogido en Apurímac que refiere cómo los gentiles —esto es los pobladores anteriores a la irrupción europea y que por lo mismo aún no habían sido cristianizados- explicaban la función que correspondía a los intihuatana. Este relato mítico fue recogido en Chuquinga (Apurímac) por Ruben Aucahuasi, quien tuvo la generosidad de compartirlo con nosotros.

Previamente expondremos algunos lineamientos generales sobre los intihuatana y en particular del soberbio intihuatana ubicado en Machu Picchu.

\section{Los intihuatana}

La voz intihuatana es gentilicio del runasimi o quechua y en su forma plural es vocalizada mediante la palabra intihuatana-cuna. Su traducción es "amarrar al Sol", giro lingüístico que sin duda nos transporta al mundo de lo sobrenatural, de lo mágico. Nadie duda que los intihuatana conformaban altares.

Con ese nombre son designadas ciertas esculturas pétreas cuyo elemento central lo constituye una pilastra de escasa altura y que apunta al cielo. Está presente dentro de un conjunto mayor, donde posiblemente se celebraron los ritos más solemnes. Por lo mismo se ubican en un lugar prominente.

Los intihuatana se encuentran siempre en sitios arqueológicos monumentales, siendo el de Pisac, en el Valle Sagrado de los Incas de Urubamba, el más imponente después del de Machu Picchu. Otro sitio arqueológico que luce este elemento sacro y que exploramos personalmente en alguna oportunidad es conocido precisamente como Intihuatana (Vischongo, Vilcashuamán, Ayacucho); también se le nombra con el apelativo de Pomacocha debido a que su perímetro incluye una pequeña laguna que lleva ese nombre.

En la obra de George E. Squier (1877) figura un dibujo que retrata a Pisac y en este conjunto una pilastra que al citado autor le fue señalada con el nombre de intihuatana. En este contexto cabe recordar que se debe a Max Uhle (1910) un estudio pionero sobre los intihuatana.

John Rowe (1946) tenía sus dudas acerca de la antigüedad prehispánica del vocablo intihuatana; esto es, sospechaba que era de data posterior a la irrupción europea. Sin embargo, debemos remarcar que la palabra intihuatana aparece ya citada en la obra de Pablo José Oricain (1790: 349), si bien tomando la forma de yntiquatana. Aunque parezca increíble, la voz intihuatana todavía sigue en uso en ciertas regiones altoandinas y en particular entre pobladores quechuahablantes. Particularmente en mitos como el recogido por Ruben Aucahuasi (Kauffmann Doig, 2013 vol. 2: 521, 528). Asimismo, la voz intihuatana figura en un relato mítico presente en la región de Ancash, dado a conocer por Alejandro Ortíz Rescaniere (1973) y vinculado al mito de Incarrí (= inca-rey); alude al poder de este personaje sobrenatural sosteniendo que "amarró el Sol para que el tiempo durara". Sin embargo, esta narración no ofrece explicación alguna acerca del porqué lo amarraría. En cambio la versión apurimeña recogida por Ruben Aucahuasi, y sobre la que nos ocuparemos más adelante, sí lo especifica. 


\section{El Intihuatana de Machu Picchu: características formales}

Con el nombre de Intihuatana de Machu Picchu se conoce a un adoratorio que acusa diversas gradientes y que va esculpido en un bloque granítico que asoma a la superficie. Se ubica en el sector superior de una colina rodeada de terrazas de cultivo o andenes y a la que se accede mediante graderías. Esto es en un lugar privilegiado, por cuanto el promontorio sobre el que se yergue el adoratorio conocido como Intihuatana sobresale en cuanto a su altitud respecto al conjunto arqueológico. El grupo escultçorico conocido como intihuatana al que nos referimos, debió ser un altar; acaso el más prominente de Machu Picchu. En cuanto a su perímetro, este alcanza 8,60 metros y su altura se eleva por 1,76 metros.

A un costado de la gran escultura granítica que al parecer imita las terrazas de cultivo, emerge un elemento tallado en forma de un prisma cuadrangular, como si se tratara de una pequeña columna que apunta al cielo. Es esta lo que con propiedad se estima fue el Intihuatana, por su traducción: “amarrar el sol”. Para dar cumplimiento al acto que señala el mito, por más ilusorio que fuese, en la práctica era menester disponer de un soporte que permitiera retener al astro rey mediante una cuerda. Se proyecta en lo alto hasta alcanzar 0,69 metros, mide 0,55 metros de ancho y su espesor es de 0,39 metros. El intihuatana presenta en su sector superior una superficie plana, si bien inclinada levemente. Si hemos de seguir las representaciones de apus o montañas sagradas que incluye Guaman Poma (c. 1600). Encima de este elemento debió estar ubicado una figura votiva.

Visto en conjunto el Intihuatana de Machu Picchu conforma una pieza escultórica abstracta. Johan Reinhard (1991: 48 y 50) esgrime que su figura se inspira en una montaña sagrada, acaso la de Huayna Picchu. Los diversos dibujos de Guaman Poma que muestran apus (montañas sagradas) (Guamán Poma c. 1600 fs. 238, 240, 261, 264, 266, 268, 270, 272, 284) van coronados por una figura humana que debe representar a la divinidad en persona, refuerzan la hipótesis de Reinhard. Acaso la Intihuatana de Machu Picchu era también coronada por una figura sacra.

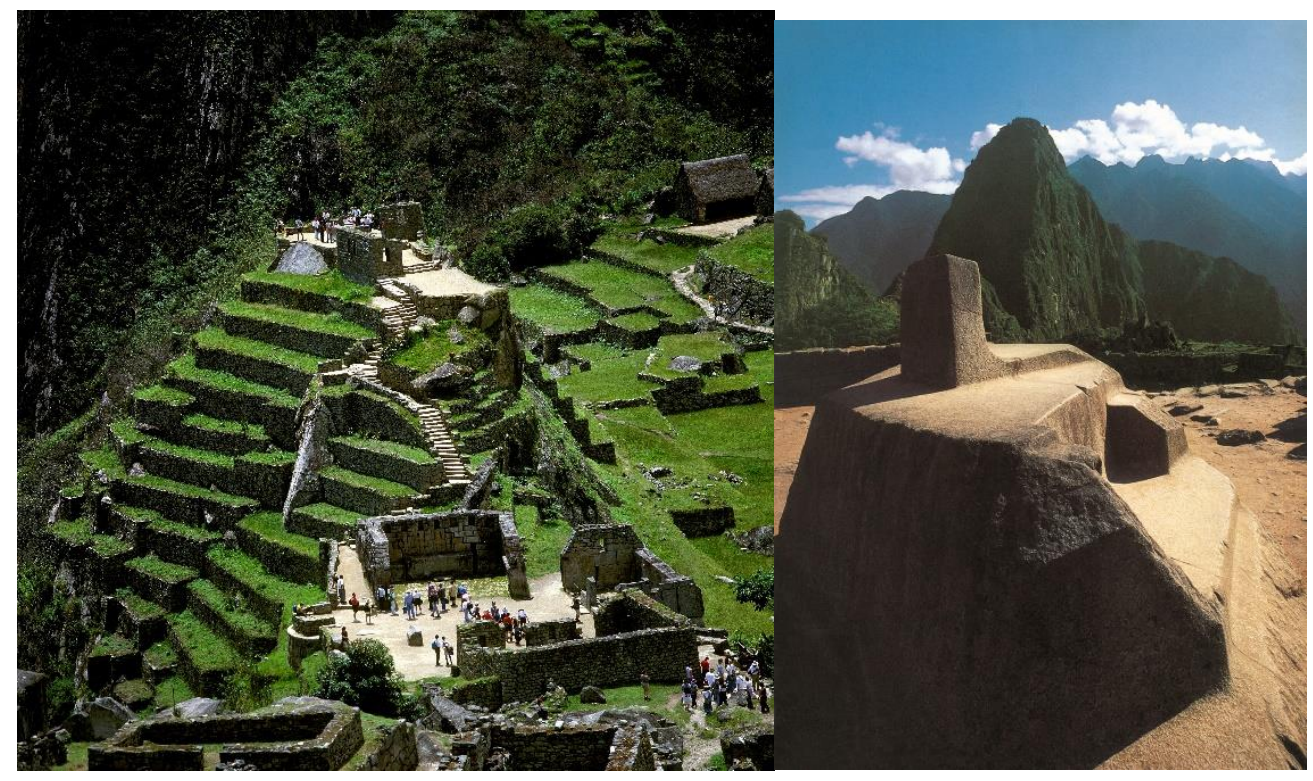

\section{Propuestas diversas sobre la función de los intihuatana}

Son diversas las propuestas en cuanto a la función que pudieron tener las esculturas pétreas conocidas como intihuatana. Una idea muy generalizada es que cumplía un rol astronómico (Zecenarro, 2004). Según esta concepción los intihuatanas habrían sido observatorios para determinar los solsticios.

Popularmente se especula que debió tratarse de un "reloj solar" que permitía observar las sombras que van proyectándose en el curso del día. Algo poco probable ya que la mayor parte del año las construcciones de Machu Picchu, en particular, están cubiertas por nubosidades que habrían impedido esta función.

\section{Un recurso mágico que permitía laborar más tiempo de lo normal}


La escasez de tierras aptas para el cultivo debido a las laderas áridas de los Andes y los estrechos valles cordilleranos obligó a los antiguos peruanos a desarrollar soluciones tecnológicas diversas para paliar esta problemática. Por ejemplo, obras de canalización y la construcción de andenes o terrazas de cultivo en las pendientes andinas. Otro recurso fue la ampliación de la frontera agraria. Esto último posiblemente fue puesto en práctica desde tiempos remotos, al ocupar los andinos sectores del flanco oriental de los Andes norteños del Perú; acaso ya en tiempos de Tiahuanaco-Huari (o Wari) y donde la población andina pasadas algunas centurias terminó por forjar una cultura sui generis, la chachapoya. Asimismo, en tiempos del Incario y sin duda bajo un proyecto estatal la comarca de Vilcabamba, ubicada en los Andes Amazónicos o flanco oriental de los Andes, fue colonizada y allí se levantaron proezas arquitectónicas como Machu Picchu (Kauffmann Doig, 2014: 39).

Tales medidas no daban resultados cuando se presentaban anomalías climáticas que eran recurrentes debido al Fenómeno de El Niño; unas veces a través de lluvias torrenciales y en otros casos mediante prolongadas sequías que, al dañar los campos de cultivo, hacían que asomara el fantasma del hambre. Contra estas calamidades de la naturaleza solo ayudaba la esperanza, expresada en una desbordante religiosidad que se exteriorizaba mediante imploraciones, ofrendas y hasta sacrificios dirigidos a los apu o montañas sagradas, con el ruego que lloviese en su debido tiempo y en su justa medida. Por otro lado se respetaba y agradecía amorosamente a la Pachamama o Madre Tierra, la divinidad benévola — representada tan solo por las áreas cultivables - y considerada como la donante directa de los comestibles; esto siempre que fuera fecundada por el agua (Kauffmann Doig, 1996, 2003).

\section{Gentilmantarimay}

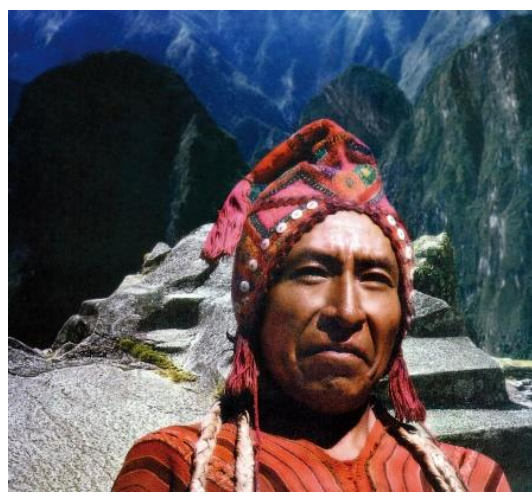

A los recursos tecnológicos que paliaban la falta de alimentos que aquejaba a los antiguos peruanos, se sumaba la laboriosidad llevada al extremo, por ejemplo para recolectar los alimentos imprescindibles para la vida. Para trabajar los campos de tal manera que abastecieran al presentarse periodos de hambruna, se requería de más horas de las que proporcionaba el día. Consideramos que así pudo originarse la saga que magnificara a los remotos antepasados, los gentiles, al atribuírseles la capacidad sobrehumana de prolongar la luz diurna a fin de extender las faenas del campo para lograr un superávit de alimentos para sortear los años aciagos.

De acuerdo al relato mítico, los gentiles tenían la potestad de amarrar el Sol, lo que se traduce en quechua o runasimi como intihuatana, esto es la misma palabra que en Machu Picchu recibe el conjunto de la escultura pétrea que hemos descrito y de la que se desprende la pilastra que recibe la misma denominación. Para amarrar al Sol se precisa de una estaca, por lo que el elemento aludido fue utilizado por los gentiles para sujetar al Sol. Y todo esto como ya se expuso para que el día durara más tiempo a fin de extender la laboriosidad en los campos y así obtener la cuota de alimentos imprescindibles para la vida y lograr un superávit de comestibles que permitiese evitar hambrunas como consecuencia de las catástrofes climáticas que los antiguos peruanos soportaban recurrentemente (Kauffmann Doig 2017, vol. 2: 709 - 733).

Seguidamente transcribimos el fragmento del relato mítico que hemos mencionado, Gentilmantarimay, que sin lugar a duda data de tiempos inmemoriales; tanto en su versión original en quechua como traducido al español:

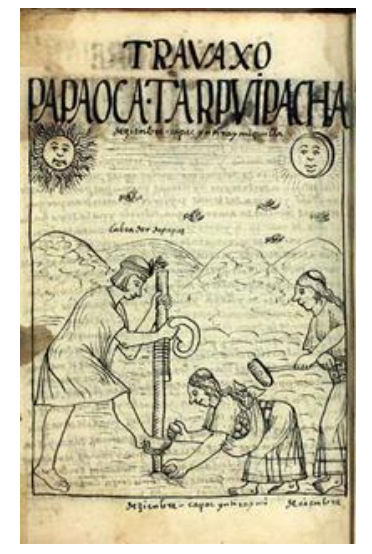

\section{Naupa runakunaqa sinchi \\ ñakarikuywansi kausayta tarisqaku.}

Monaraq achihaymanta, allin tuta yaykuykamas llank'asqaku.

Paykkunapaqsi, p’unchauqa pisillaña kapusqa.

Chaysi, pallay chumpikunawan WATASQAKU, sapay p'unchau usianankama.
Los hombres antiguos con muchas

Dificultades encontraban las subsistencias.

Desde antes del amanecer, hasta bien entrada la noche, trabajaban.

Para ellos el día ya era muy corto.

INTITA Por eso, se dice, amarraban al sol, llamk'ay con cintas artísticas cada día hasta terminar el trabajo. 
El mito Gentilmantarimay fue recogido hace algunas décadas en Chuquinga (Apurímac) por el lugareño Ruben Aucahuasi, quien tuvo la gentileza de narrárnoslo.

Esta narración indica explícitamente la función que habrían tenido los intihuatana y por tanto nos permite interpretar con certeza cuál fue el uso de estas tallas, siendo la más conspicua la de Machu Picchu

\section{REFERENCIAS BIBLIOGRAFICAS}

GUAMAN POMA DE AYALA (Phelipe)

c. 1600 Nueva coronica y buen gobierno (París 1936). MS.

\section{KAUFFMANN DOIG (Federico)}

1996 "Gestación y rostro de la civilización andina" Lienzo (Revista de la Universidad de Lima) 17: 9-55. Lima.

2003 "Los dioses andinos: dioses del sustento". Precolombart 4-5 (20012002): 55-69. Barcelona.

2014 Machu Pichhu / más allá de la maravilla arquitectónica. Lima.

2017 Machu Picchu. Sortilegio en piedra/Enchantment in Stone. 2 vols. Lima.

\section{ORICAIN (Pablo José)}

1790 "Compendio breve de los discursos varios sobre diferentes materias y noticias geográficas comprehensivas a este obispado del Cusco". Víctor M. Maurtua: Juicio de Limites entre Perú y Bolivia 2: 321-337. Barcelona (1906). MS.

\section{ORTÍZ RESCANIERE}

1973 De Adaneva a Incarrí / una visión indígena del Perú. Lima.

\section{REINHARD (Johan)}

1991 Machu Picchu / The Sacred Center. Lima.

\section{ROWE (John)}

1946 "Inca Culture at the time of the Spanish Conquest". Handbook of South
American Indians 2: 183-330.

Washington, D.C.

SQUIER (E. George)

1877 Perú / Incidents of travel and exploration in the land of the Incas. New York.

\section{UHLE (Max)}

1910 "Datos para la explicación de los intihuatanas". Revista Universitaria (Universidad Nacional Mayor de San Marcos) 5 (1): 325-352. Lima.

ZECENARRO BENAVENTE (Germán)

2004 "Saywas y sugangas, usnus y asientos del Sol / Instrumentos de medición astronómica”. Arkinka 106: 86-98. Lima. 